\title{
Faris Michaele: trajetória de um intelectual moderno
}

\author{
Faris Michaele: trajectory of a modern intellectual
}

Névio de Campos ${ }^{*}$

Elisa Marchese

\begin{abstract}
Resumo: Este artigo objetiva analisar a trajetória intelectual de Faris Antônio Salomão Michaele (19111977) e problematizar sua concepção de educação. Faris Michaele nasceu no município de Mococa, interior do Estado de São Paulo, e na infância veio com a família para Ponta Grossa. Sua escolarização iniciou no Colégio São Luiz (Ensino Primário), continuou no Colégio Regente Feijó (Ensino Secundário) e foi concluída na Faculdade de Direito do Paraná. Sua trajetória está marcada por participar e dirigir a criação de diversos espaços culturais e educativos, entre os quais o Centro Cultural Euclides da Cunha (1947) e a Faculdade de Filosofia, Ciências e Letras de Ponta Grossa (1949), bem como pela atuação no magistério de Ensino Secundário e Ensino Superior. A análise desse personagem apoia-se em Bourdieu e nas correspondências enviadas e recebidas pelo Centro Cultural Euclides da Cunha e pelo próprio Faris Michaele, nas obras que compõem o acervo da sua biblioteca pessoal, bem como nos artigos escritos por ele e sobre ele. À luz dos conceitos bourdieusianos e do corpus documental é possível afirmar que, em conjunto com uma camada social detentora de capital cultural, Faris Michaele estabeleceu uma série de instituições, objetivando aglutinar uma parcela da intelectualidade dos Campos Gerais e divulgar uma visão de mundo sistematizada pelas doutrinas filosóficas, científicas, literárias e educativas que se associavam à tradição antropocêntrica.
\end{abstract}

Palavras-chave: Faris Michaele. Trajetória intelectual. Educação. Modernidade.

Abstract: This article aims to analyze Faris Antônio Salomão Michaele’s intellectual trajectory (19111977) and discuss his conception of education. Faris Michaele was born in a borough called Mococa which is located in the countryside of Sao Paulo. When he was a child, his family moved to Ponta Grossa where he began to study at Colégio São Luiz (primary school), continued at Colégio Regente Feijó (secondary school) and graduated at Faculdade de Direito do Paraná. Michaele is recognized for participating and directing the creation of many spaces dedicated to culture and education such as Centro Cultural Euclides da Cunha (1947) and Faculdade de Filosofia, Ciências e Letras de Ponta Grossa (1949). He is also known for working as a secondary school teacher and a professor in Higher Education. The analysis of this character is based on Bourdieu and on the correspondences exchanged by Centro Cultural Euclides da Cunha and Faris Michaele. It is also based on the titles that compose his private library as well as on the articles written by him and about him. In the light of Bourdieu's concepts and on the corpus it is possible to assert that Faris Michaele together with a social class which held the cultural capital established a number of institutions with the purpose of agglutinating part

\footnotetext{
* Doutor em Educação. Professor do Programa de Pós-Graduação em Educação na Universidade Estadual de Ponta Grossa. E-mail: nmestrado@ig.com.br

* Doctor in Education: Professor at the Post-Graduate Program in Education at the State University of Ponta Grossa. E-mail: nmestrado@ig.com.br

** Acadêmica do curso de Pedagogia da Universidade Estadual de Ponta Grossa. Marchese é bolsista do CNPq. E-mail: elisamarchese@bol.com.br

** Undergraduate student at the Pedagogy Course at the State University of Ponta Grossa. Marchese was granted an Undergradute Research scholarship from the CNPq. E-mail: elisamarchese@bol.com.br
} 
of Campos Gerais intellectuality and disseminating a worldview systematized by philosophy, science, literature and educational doctrines that were associated to the anthropocentric tradition.

Keywords: Faris Michaele. Intellectual trajectory. Education. Modernity.

\section{Introdução}

Este artigo objetiva analisar alguns aspectos da trajetória intelectual de Faris Antônio Salomão Michaele (1911-1977) e problematizar sua concepção educativa. Tal análise apoia-se nos conceitos de campo, habitus, intelectual e trajetória, de Pierre Bourdieu.

O conceito de campo refere-se a certos espaços de posições sociais onde se produzem, consomem e classificam-se determinados tipos de bens. O interior desse espaço de força e luta é caracterizado pela incessante busca do controle da produção, do direito de legitimidade da classificação e hierarquização dos bens produzidos pelos indivíduos (NOGUEIRA; NOGUEIRA, 2009). Isto é, “campo é um espaço de relações objetivas entre indivíduos, coletividades ou instituições, que competem pela dominação de um cabedal específico” (BOURDIEU, 1983, p.197).

Atrelado ao conceito de campo, está o de habitus. Nessa inter-relação, o segundo é constituído e constituinte do primeiro. Habitus é compreendido como um sistema de disposições duráveis, estruturado conforme o meio social dos indivíduos, que funcionam como estruturas estruturantes. Dito de outra forma, habitus é o princípio gerador e estruturador das práticas e representações (BOURDIEU, 1983).

Os conceitos de intelectual e trajetória têm destaque neste texto, pois a escrita da história intelectual da educação a partir da análise do funcionamento de uma sociedade intelectual das "suas práticas, suas estratégias e seus habitus” (SILVA, 2002, p.12), evoca a necessidade do entendimento das contradições e do papel social desses mediadores entre as estruturas e os estruturantes.

Para Bourdieu (1996a), o intelectual é um ser paradoxal, um personagem bidimensional que manifesta perícia e autoridade específica nas atividades políticas e culturais exteriores ao campo que integra, ou seja, ao campo intelectual autônomo.

O intelectual é uma personagem bidimensional que só existe e subsiste como tal se (e apenas se) for investido de uma autoridade específica, conferida por um mundo cultural autónomo (quer dizer, independente dos poderes religiosos, políticos, económicos) cujas leis específicas respeita, e se (apenas se) cometer essa autoridade específica em lutas políticas. Longe de existir, como correntemente se pensa, uma antinomia entre a busca da autonomia (que caracteriza a arte, a ciência ou a literatura ditas “puras”) e a busca da eficácia política, é aumentando a sua autonomia (e, por isso, entre outra coisas, a sua liberdade crítica perante os poderes) que os intelectuais podem aumentar a eficácia de uma acção política cujos fins e meios encontram o seu princípio na lógica específica dos campos de produção intelectual. (BOURDIEU, 1996a, p. 380).

Desse modo, a trajetória intelectual mostra-se como um meio de compreensão dos inúmeros papéis, posições e eventuais contradições na carreira intelectual, pois diferentemente das biografias comuns, a trajetória descreve os 
Estados sucessivos da estrutura da distribuição dos diferentes tipos de capital que estão em jogo no campo considerado. É evidente que o sentido dos movimentos que levam de uma posição a outra (de um editor a outro, de uma revista a outra, de um bispo a outro etc.) define-se na relação objetiva entre o sentido dessas posições no momento considerado, no interior de um espaço orientado. Isto é, não podemos compreender uma trajetória, a menos que tenhamos previamente construído os estados sucessivos do campo no qual ela se desenrolou; logo, o conjunto de relações objetivas que vinculam o agente considerado - pelo menos em certo número de estados pertinentes do campo - ao conjunto dos outros agentes envolvidos no mesmo campo e que se defrontaram no mesmo espaço de possíveis. (BOURDIEU, 1996b, p. 82).

Diante dessa opção teórica, procura-se ao longo do texto compreender a vida de Faris Michaele, entendendo as contradições e transformações incessantes que compõem sua trajetória.

Com o intuito de reconstituir determinados aspectos da trajetória de Faris Michaele, foram selecionados e analisados alguns documentos impressos, como, por exemplo, as correspondências do Centro Cultural Euclides da Cunha e do próprio Michaele; ${ }^{11}$ a relação de obras sobre educação que compõem o acervo da biblioteca pessoal desse intelectual; e os artigos escritos por ele e sobre ele. Tal documentação é entendida como construção da própria memória de Michaele, pois:

Documento não é qualquer coisa que fica por conta do passado, é um produto da sociedade que o fabricou segundo as relações de forças que aí detinham o po-

\footnotetext{
${ }^{1}$ As correspondências analisadas compreenderam o período de 1936 a 1952.
}

der. Só a análise do documento enquanto monumento permite à memória coletiva recuperá-lo e ao historiador usá-lo cientificamente, isto é, com pleno conhecimento de causa. (LE GOFF, 1990, p.545).

A crítica documental é um aspecto importante no processo analítico da escrita histórica, pois indica o modo como o historiador dialoga com os documentos, isto é, com os indícios e sinais que permitem interpretar determinados aspectos de um acontecimento. Nesse sentido, a observação de Le Goff reitera nossa pretensão - reconstituir algumas experiências de Faris Michaele -, mas sem desconsiderar que os documentos (cartas, discursos, acervo da biblioteca) são selecionados por quem os produziu, preservou e por nós que os utilizamos para explicar determinadas facetas desse personagem da história paranaense.

Assim, a partir de Bourdieu, do corpus documental e da crítica metodológica de Jacques Le Goff, buscamos contextualizar a trajetória intelectual de Faris Michaele. Apresentam-se, na sequência, alguns aspectos da formação acadêmica desse personagem, bem como sua participação em diferentes projetos culturais e formativos estabelecidos em Ponta Grossa, particularmente na Faculdade de Filosofia, Ciências e Letras e no Centro Cultural Euclides da Cunha, objetivando explicitar a hipótese de que Michaele articulava sua intervenção intelectual aos ideários da modernidade e da pedagogia moderna.

\section{Trajetória escolar e profissional de Faris Michaele}

Natural do município de Mococa, interior do estado de São Paulo, Faris Michaele nasceu em 3 de setembro de 1911, filho de Antônio Salomão Michaele e Hada Michaele. 
Aos seis anos de idade, Faris Michaele, juntamente com sua família, passou a residir na cidade de Ponta Grossa, interior do estado do Paraná. A família Michaele, oriunda do Líbano, instalou-se no município e dedicou-se ao comércio, como a maioria dos imigrantes na época, visto que a cidade enfrentava um período de crescimento econômico e social significativo. Tal afirmação é evidenciada por Carmencita Ditzel: “Ponta Grossa respirava um 'clima urbano', havia bandas musicais que disputam o espaço para apresentações, cinema, luz elétrica, associações beneficentes e hospital” (DITZEL, 2007, p. 49). Segundo Rosângela Zulian, de tal condição resultou que "a região de Ponta Grossa passou a configurar um centro de atração não só para aqueles advindos do meio rural, como para outros migrantes, nacionais e estrangeiros" (ZULIAN, 1998, p. 42).

Nesse contexto, Faris Michaele trabalhava eventualmente no comércio da família, pois "foi poupado e destinado a estudar" (WANKE, 1998, p. 26). E a dedicação do menino é revelada desde a infância, pois a exemplo de seu progenitor, também poliglota, dominava três línguas completamente diferentes: o árabe, o alemão e o português.

Na vida adulta de Michaele um dos aspectos de seu reconhecimento intelectual dizia respeito ao domínio fluente de diferentes línguas. Tal acúmulo de capital cultural era motivo de admiração de muitos, inclusive de Enrique de Gandía, amigo de Faris Michaele residente em Buenos Aires, que em carta enviada no dia 17 de junho de 1948 escreveu: "Estoy asombrado de su domínio del portugués, español, francés y inglês. [...] Es en verdad extraordinario este 'poliglotismo' suyo y es hermoso su sentido altamente poético y panamericanista”.

Valfrido Piloto, no jornal Diário do Paraná, edição do dia 7 de março do ano de
1974, sintetiza a trajetória escolar e os anos de magistério de Faris Michaele, ao mencionar que:

Vindo com seis anos para Ponta Grossa, o piá nascido em Mococa (SP) passou pelas aulas do padre Lux, no "São Luiz", cujos rigores eu também aguentara noutros tempos. Criado no Ginásio "Regente Feijó”, foi logo da primeira turma, e ali institui o Grêmio Literário "Visconde de Taunay", e mais a biblioteca e ainda o inevitável "O Fanal". Bacharelado em direito, vai lecionar naquele ginásio, até se aposentar. Nesse meio tempo, coopera na Fundação da Faculdade de Filosofia, Ciências e Letras de Ponta Grossa, onde assume durante etapas diversas, Antropologia, Língua Tupi, Literatura Hispano-Americana, Etnografia, Português, Inglês e Castelhano, e na Fundação da Faculdade de Direito, com a cátedra de Introdução à Ciência do Direito.

Faris Michaele foi aluno da primeira turma no Ginásio Regente Feijó, em 1927. Sua passagem pela instituição revelou seu papel de liderança cultural, pois fundou o Grêmio Literário Visconde de Taunay e o jornal escolar denominado "O Fanal" (WANKE, 1998).

Após se formar em humanidades no ano de 1931, Faris Michaele ingressou no ano seguinte na Faculdade de Direito do Paraná, em Curitiba. O estudante universitário "filiou-se ao movimento integralista de Plínio Salgado" (DITZEL, 1998, p. 172) e continuou sua atividade política como integrante do Partido Social Democrático (PSD), em Ponta Grossa.

A partir do exposto nota-se que a trajetória escolar de Faris Michaele foi marcada por instituições escolares de renome, como, por exemplo, o Colégio São Luiz e o Ginásio Regente Feijó. O Colégio São Luiz (da Congregação Verbo Divino), no qual Faris 
Michaele iniciou seus estudos, foi fundado pelo Padre João Lux, em 1906. A instituição atendia, exclusivamente, meninos e ofertava o ensino primário norteado pelo seguinte currículo: álgebra, francês, alemão, português, ciências naturais e história da civilização (WANKE, 1998, p. 25-26).

A continuação dos estudos de Faris Michaele se dá no Colégio Regente Feijó, fundado em 28 de março de 1927, após três anos de funcionamento da primeira Escola Normal Primária de Ponta Grossa. A criação do Colégio revela a preocupação da sociedade moderna com a educação, já que esta era elemento definidor no status da cidade (MARÇAL, 2006).

Entretanto, apesar dos longos anos dedicados à formação, o bacharel em Direito exerceu a profissão de advogado por pouco tempo, pois “já demonstrara não ter inclinação para o comércio, não se sentiu tampouco atraído pelo dia-a-dia da advocacia. Assim, restava-lhe o magistério, para o qual realmente tinha pendor" (WANKE, 1998, p. 36).

Faris Michaele dedicou-se ao magistério no Ginásio Regente Feijó, no período de 1937 até 1967. Também lecionou nos cursos de Letras e História da Faculdade de Filosofia, Ciências e Letras de Ponta Grossa e na Faculdade de Direito. Porém, sua ação extrapolava os muros escolares. Essa condição é notável devido à preocupação de Michaele com a cultura, que resultou na criação do Centro Cultural Euclides da Cunha e nos longos anos de colaboração no "Diário dos Campos” e no “Jornal do Paraná”, nos quais publicou parte de suas aulas proferidas na universidade e de sua obra literária.

Diante dos fatos, fica evidente que a trajetória profissional de Faris Michaele esteve marcada pela ação educativa de diferentes modos e enfoques, tanto no sentido lato quanto no sentido estrito, pois esteve envolvido em múltiplos espaços de sistematiza- ção e difusão de visões de mundo e exerceu funções educativas diretas como professor e coordenador de atividades pedagógico-administrativas.

A extensiva produção e participação desse intelectual nos principais espaços e meios de difusão cultural de Ponta Grossa, do Paraná, do Brasil, e em diversos lugares estrangeiros, deve-se ao acúmulo de capital cultural sob seus três estados - incorporado, objetivado e institucionalizado - postulados por Pierre Bourdieu. O primeiro estado do capital cultural "exige uma incorporação que, enquanto pressupõe um trabalho de inculcação e de assimilação, custa tempo que deve ser investido pessoalmente pelo investidor.” (BOURDIEU, 2007, p. 74). Esse estado revela-se desde o início da formação de Faris Michaele, quando o menino é poupado do trabalho para estudar. Já o estado objetivado do capital cultural diz respeito aos bens culturais (livros, quadros, dicionários, instrumentos, máquinas etc.), os quais foram estudados nesta pesquisa, em especial o acervo pessoal de Faris Michaele, composto por aproximadamente oito mil obras. Por fim, o capital cultural institucionalizado refere-se aos certificados escolares, aos diplomas que fizeram parte da trajetória escolar e profissional de Faris Michaele como forma de reconhecimento e certificação da competência cultural e intelectual desse personagem.

\section{Presença de Faris Michaele em ambientes culturais}

A vinculação de Faris Michaele aos espaços culturais de Ponta Grossa é exaltada de tal forma em sua biografia que o autor Eno Theodoro Wanke (1998) utiliza a expressão "Ponta Grossa 'antes de Faris' e 'depois de Faris"', a fim de demonstrar a grandiosidade dos feitos desse intelectual. Segundo Wanke, 
antes de Faris Michaele, Ponta Grossa era voltada para as atividades comerciais, industriais e agrícolas. Entretanto, depois de Faris Michaele começa a época de fastígio cultural, os “anos de ouro”.

Porém, é possível relativizar a afirmação de Wanke, pois, conforme Eliezer Souza (2010, p. 61),

Os imigrantes preservavam alguns dos seus traços culturais, como religião, hábitos alimentares, festas e clubes sociais. Essas características, somadas às da população local, garantiram à Ponta Grossa uma relativa riqueza cultural. [...] Portanto, o desenvolvimento cultural ponta-grossense já tomava forma em fins do século XIX.

Diferentemente da afirmação de Wanke (1998) a respeito da biblioteca do Centro Cultural Euclides da Cunha, apontada como a primeira da cidade, Ditzel (2007, p.49) sustenta que Ponta Grossa tinha um desenvolvimento cultural significativo, "um teatro (1873) e uma biblioteca (1876)” antes mesmo do nascimento de Faris Michaele.

Diante dessas passagens, percebe-se a exaltação de Faris Michaele em sua biografia escrita por Eno Theodoro Wanke, atitude típica que faz com que "certas categorias de escritores sejam propensas a escrever suas memórias e que outras se prestem como objetos de um culto póstumo através de biografias." (MICELI, 2001, p. 83). Em nossa avaliação, a assertiva de Miceli mostra-se pertinente para relativizar as afirmações de Wanke, pois "as biografias tratam quase sempre de escritores que se consagraram ainda em vida ou, então, de autores relegados em vida e que são repostos em circulação por conta de estratégias de combate a que recorrem certas igrejas literárias em conjunturas posteriores da vida intelectual” (MICELI, 2001, p. 84). Faris Michaele se consagrou em vida, o que explica a razão de ter sido objeto de biografia póstuma, escrita por seu antigo amigo.

Todavia, apesar das contradições e exageros, Faris Michaele teve seu nome ligado à criação, direção e participação em várias instituições ponta-grossenses, como a Faculdade de Filosofia, Ciências e Letras; a Faculdade de Direito; o Instituto Histórico, Geográfico e Etnográfico de Ponta Grossa; a União Brasileira de Trovadores de Ponta Grossa; o Centro Cultural Brasil - Estados Unidos; o Centro Cultural Euclides da Cunha; e o Museu Campos Gerais. (DITZEL, 1998).

Entre seus feitos o mais lembrado é o Centro Cultural Euclides da Cunha (CCEC), que iniciou suas atividades no mês de março do ano de 1948. O CCEC foi

\section{Uma sociedade civil destinada a congre- gar intelectuais, prestando-lhes apoio cultural e moral, cooperando, assim, para o desenvolvimento da literatura, das ci- ências e das artes, bem como estimular o intercâmbio de idéias com o resto do país e das Américas. (ESTATUTO DO CCEC, 1948 apud DITZEL, 1998, p. 63).}

Esse Centro dispunha de uma biblioteca aberta à comunidade e publicava trimestralmente o jornal “Tapejara”. A sociedade civil declarava-se uma instituição apolítica. Essa pretensão manifesta a preocupação com a liberdade de pensamento, pois “o grupo euclidiano local apresentava grande diversidade de concepções. Comunistas, integralistas, udenistas, sociais democratas entre outros pertenciam ao Centro” (DITZEL, 2007, p. 239). O sentido da terminologia "apolítica" deve ser reconhecido como preocupação com a função específica dos intelectuais, pois eles buscam dar ao campo cultural um grau de autonomia em relação aos campos da política e da religião. No entanto, essas independências são sempre relativas. Tal tentativa constitui 
a condição bidimensional do intelectual, conforme explicitou Bourdieu: reclama a autonomia intelectual, mas em nome de seu capital simbólico (reconhecimento/perícia) participa em outros campos sociais.

Para além do CCEC e de Ponta Grossa, Faris Michaele esteve presente, também, em instituições paranaenses. Ocupou a $12^{\mathrm{a}}$ cadeira da Academia Paranaense de Letras, como sucessor do Professor Dr. José de Sá Nunes. Em 25 de março de 1968, foi recepcionado por Osvaldo Pilotto, que no discurso publicado na Revista Minerva (1968) enalteceu Michaele parafraseando Fernando de Azevedo:

Satisfação de se ter posto em contacto com o seu alto espírito através desses estudos, lidos com o mais vivo interesse e com a expressão de sua simpatia, a esperança de aproveitar novas oportunidades para tão amável convívio. (PILOTTO, 1968, p. 6).

No mesmo discurso, Osvaldo Pilotto rememorou os feitos de Faris Michaele e afirmou: "[...] brilhante, pela sua cultura e pelas suas qualidades didáticas, na sua vida de professor. É escritor de alto mérito.” (PILOTTO, 1968, p. 6).

Michaele também teve seu nome ligado a entidades e associações nacionais e estrangeiras. Ditzel (1998) elenca as 60 principais, dentre as quais destacamos as seguintes: Academia Universal de $\mathrm{Hu}-$ manidades, de Buenos Aires; Instituto Argentino de Críticos Literários; Instituto de Cultura Americana de La Plata; Asociación de Escritores de la Provincia de Buenos Aires; Instituto de Etnología, Historia y Folklore de Tucumán; Academia de Cultura de Asunción, Asociación Internacional de la Prensa de Montevideo; Asociación de Escritores y Artistas Americanos, de La Habana; American International Academy, de Nova York; Confraternité Balzacienne de
Paris; Acadímie Ansaldi de Paris; Accademia Letteraria Araldica Scientifica, de Treviso, Itália; Accademia Letteraria Scientifica Internazionale, de Nápoles; Internatinal Council of Musems, de Londres. Para Osvaldo Pilotto (1968, p. 7), "isto é fruto de uma atividade intelectual intensiva”.

A comunicação de Faris Michaele com esses diversos espaços culturais ocorria por meio de correspondências, envio de obras e publicações em periódicos. E o conteúdo das correspondências revela a admiração do trabalho intelectual do personagem considerado ponta-grossense e, até mesmo, questionamentos sobre sua permanência na cidade interiorana.

Para evidenciar os apontamentos citados, transcrevemos um trecho de uma carta de Alcântara Nogueira do dia 22 de janeiro de 1949: "Vejo que sua atividade intelectual é imensa; é uma ventura encontrar-se neste Brasil homens com esse idealismo, concorrendo, objetivamente, para o levantamento do nosso nível cultural". Entre os interlocutores de Faris Michaele estavam Gilberto Freyre, Érico Veríssimo, Roquete Pinto, Cândido Rondon, Luís da Câmara Cascudo, Roger Bastide, Valfrido Piloto e Raul Gomes, entre outros. As correspondências, assim como o acervo da biblioteca pessoal de Faris Michaele, encontram-se arquivados no Centro de Pesquisa em História, pertencente ao Departamento de História da Universidade Estadual de Ponta Grossa, desde 1998, ano em que a esposa desse intelectual, Amélia Oberg, efetuou a doação.

O vínculo entre Faris Michaele e diferentes instituições culturais, mantido por meio de cartas, publicações e obras, fortalecia sua ação intelectual instigando a criação de instituições, mobilização, formação de grupos, organização de projetos educativos e outros. Desse modo, esse personagem 
acumulava capital e poder simbólico que lhe permitiam reconhecimento no campo intelectual e cultural. Tal assertiva pode ser compreendida à luz da afirmação de Bourdieu (2008, p. 59): “[...] o peso dos diferentes agentes depende de seu capital simbólico, isto é, do reconhecimento institucionalizado ou não, que recebem de um grupo [...]”.

Diante do exposto, é possível afirmar que Faris Michaele tem sua trajetória marcada por quatro características definidoras dos intelectuais modernos. Segundo Carlos Eduardo Vieira (2007), tais características seriam: a) sentimento de pertencimento a um grupo; b) sentimento de missão social; c) possibilidade de mudança e reorganização social por meio da educação; d) entendimento do Estado como agente político responsável pela efetivação do projeto moderno.

O sentimento de pertencimento permeia grande parte dos feitos de Faris Michaele, já que ele, embora tenha sido questionado muitas vezes, nunca deixou a cidade interiorana. Além disso, preocupouse com projetos locais, unindo-se aos pares para criar inúmeras instituições culturais e educativas (jornais, centros literários, faculdade). Vinculado ao processo de criação de instituições sociais, estava o desejo de missão social, isto é, a crença de que tais ambientes culturais seriam o baluarte da renovação e reorganização da sociedade ponta-grossense. Nesse sentido, Faris Michaele foi um agente criador e participante de instituições culturais e formativas que objetivavam conformar novas visões de mundo entre os habitantes de Ponta Grossa. Por fim, ele entendia o Estado como um agente político importante para efetivação do projeto moderno, pois pautado na "educação como salvadora da pátria”, Faris Michaele lutou junto com outros intelectuais pela criação da Faculdade de Filosofia, Ciências e Letras de Ponta Grossa.
O objetivo foi uma contextualização histórica da trajetória escolar e profissional de Faris Michaele, enfatizando a contínua preocupação desse personagem com a criação de espaços com capacidade para catalisar as principais lideranças dos Campos Gerais, assim como sistematizar projetos culturais e educativos para transformar os modos de ser dos ponta-grossenses. A trajetória de Michaele indica o sentido moderno de intelectual: indivíduo comprometido não só com as letras, mas também e, sobretudo, com a organização de instituições culturais e políticas. É nesses termos que postulamos o conceito de intelectual bidimensional como hipótese explicativa da trajetória desse personagem paranaense.

\section{Faris Michaele e os ideais da modernidade e pedagogia moderna}

Em meados da década de 1920, o regime republicano passou a ganhar forças no Brasil, marcando a passagem da vida rural para a vida urbana e industrial. O discurso da modernidade era fundamentado num projeto moderno de educação que tinha a finalidade da moralização do povo, criando os sentimentos de indivíduos ávidos pelo trabalho e pertencentes a uma nação.

Nesse contexto, “a pedagogia e os pedagogos ilustrados procuram atualizar as instituições escolares à modernidade capitalista” (MONARCHA, 1989, p. 12), surgindo assim um movimento organizado e pensado por um grupo de intelectuais preocupados com os rumos da educação brasileira, o Movimento da Escola Nova.

Esse “novo” saber pedagógico prezava, principalmente, por uma educação pública, gratuita, laica e de dever do Estado, para todos. Com esses princípios, intelectuais como Fernando de Azevedo, Lourenço Filho, Anísio Teixeira e tantos 
outros assinaram o Manifesto dos Pioneiros da Educação de 1932, documento que refletia os ideais do movimento e apontava caminhos para uma reconstrução social, por meio da reconstrução educacional.

Tal movimento teve repercussão e adeptos em muitos lugares do Brasil, pois os centros urbanos estavam sintonizados ao ideal de modernidade e, também, precisavam preparar-se para as exigências do novo mundo capitalista. No Paraná, o novo saber pedagógico chegou por intermédio de intelectuais envolvidos ao movimento renovador: Dario Vellozo e Erasmo Pilotto, os quais tiveram laços de amizade com Faris Michaele.

Maria Lúcia de Andrade (2007), em estudo sobre a trajetória de Dario Vellozo, apresenta-o como o precursor da corrente laica da educação em Curitiba.

Vellozo propôs e estimulou a implantação da escola moderna no estado paranaense, pautada em um programa que buscava a laicização, a publicização, a moralização, a higienização e a universalização do ensino, a partir das reformas de conduta que adaptassem e corroborassem para uma prática de desenvolvimento tanto material quanto cultural, e de fomento à produção agrícola e na organização do trabalho para a vida: disciplinado, produtivo e solidário. (ANDRADE, 2007, p.199-200).

A preocupação de Dario Vellozo com a educação impactou a primeira proposta sistematizada de reforma do ensino em Curitiba, o Plano e Programa de Estudos. Esse projeto foi elaborado nos moldes dos ideais modernos, mas sofreu recusa no Congresso Legislativo do Estado do Paraná. O grupo renovador paranaense criou, também, o Instituto Neo-Pitagórico (1909), composto por um grupo de intelectuais e estudantes do Ginásio Paranaense e da Escola Normal, cujo objetivo era libertar as mentes das travas da religião, em especial, da igreja católica.
Outro personagem que se destacou na defesa dos princípios do Movimento pela Escola Nova no Paraná foi Erasmo Pilotto em sua atuação como professor, organizador de escolas, administrador público e produtor de uma vasta obra pedagógica (VIEIRA; MARACH, 2007).

De acordo com Vieira e Marach (2007, p. 272),

Pilotto colaborou com Cecília Meireles, signatária do celebre Manifesto de 1932, nas paginas do Diário de Noticias. Atuou, também, na V Conferencia Nacional de Educação como delegado do Paraná. Ao lado das propostas do MEN, Pilotto participou dos debates que preparavam as teses da ABE para o anteprojeto da Constituinte de 1934.

Esses dois nomes citados tiveram laços de amizade com Faris Michaele, particularmente Erasmo Pilotto. Em 1931, Erasmo Pilotto assumiu a cadeira de Português e a direção da Escola Normal de Ponta Grossa, permanecendo até o final de 1932. De acordo com Rossano Silva (2009), em notas autobiográficas Erasmo Pilotto destacou a homenagem recebida de Faris Michaele. Segundo Silva, Faris Michaele afirmou:

[...] nos reunimos vários estudantes e estudiosos de Ponta Grossa e Curitiba, alguns já falecidos. E era de ver, então, que lhe proporcionávamos, ao gigante da cultura geral, que era Erasmo, o nosso Erasmo, também humanisticamente apaixonado pelos problemas da cultura e do saber. [...] não será difícil, agora, formar uma idéia de sua benéfica atuação entre nós. Além de encorajar a cultura no sentido genérico do termo, foi sempre um grande e sincero amigo que ganhamos, os ponta-grossenses de nascimento ou coração, não importa. (SILVA, 2009, p. 119). 
Os laços de amizade de Michaele podem ser reconstituídos pela relação institucional que ele estabelecia, assim como a partir de suas correspondências e da biblioteca pessoal. O acervo da biblioteca pessoal de Faris Michaele, composto de aproximadamente 7 mil livros, possui 101 livros que tratam da temática educacional. Desse conjunto, destacam-se os seguintes autores: Fernando de Azevedo, Rui Barbosa, Anísio Teixeira, Emile Durkheim, Gustave Flaubert, Leonel França, William Heard Kilpatrick, John Dewey, Lourenço Filho, Karl Manhheim, Jean Piaget, Valfrido
Piloto, Erasmo Pilotto, Osvaldo Pilotto, Jacques Barzun, José Maria Belo, Paulo Bonavides, Raul Briquet, Roger Cousinet, Frederik Gruber, Geoger Gusdorf, René Hubert, Claude Levi-Strauss, Jean-Jacques Rousseau e Karl Marx.

Neste momento, gostaríamos de destacar algumas obras que compõem seu acervo pessoal. A partir da análise da lista das obras do acervo foram organizados três quadros que retratam as principais bibliografias de autores estrangeiros, nacionais e paranaenses que se aproximam da Pedagogia Moderna.

QUADRO 1 - Relação de obras de autores estrangeiros que compõem o acervo da Biblioteca Pessoal de Faris Michaele

\begin{tabular}{|c|c|}
\hline \multicolumn{2}{|c|}{$\begin{array}{l}\text { Relação de obras de autores estrangeiros que compõem o acervo da } \\
\text { Biblioteca Pessoal de Faris Michaele }\end{array}$} \\
\hline Autores & Obras \\
\hline Emile Durkheim & $\begin{array}{l}\text { As regras do método sociológico (1960); } \\
\text { Educação e sociologia. }\end{array}$ \\
\hline Jean Jacques Rousseau & $\begin{array}{l}\text { Discurso sobre el origen de La desigualdad } \\
\text { entre los hombres (1923); } \\
\text { Émile ou de l'éducation (I, II). }\end{array}$ \\
\hline Jean Piaget & $\begin{array}{l}\text { Psicologia da inteligência (1961); } \\
\text { Psicologia da inteligência (1967); } \\
\text { Intoduction a l'epistemologie genétique I, II, } \\
\text { III (1950); } \\
\text { O nascimento da inteligência na criança } \\
\text { (1970); } \\
\text { Estudos de psicologia (1964); } \\
\text { A linguagem e o pensamento da criança (1959). }\end{array}$ \\
\hline Karl Marx & $\begin{array}{l}\text { O capital (1956); } \\
\text { A origem do capital; } \\
\text { Los fundamentos del marxismo. }\end{array}$ \\
\hline Karl Mannheim & $\begin{array}{l}\text { Ideologia e utopia: introdução à sociologia do } \\
\text { conhecimento (1956); } \\
\text { Sociologia do conhecimento (1967). }\end{array}$ \\
\hline John Dewey & $\begin{array}{l}\text { El hombre y sus problemas (1952); } \\
\text { Human nature and conduct (1930; } \\
\text { Reconstruction in philosophy (1951); } \\
\text { Liberdade e cultura (1953); } \\
\text { Como pensamos (1953). }\end{array}$ \\
\hline Willian Heard Kilpatrick & Educação para uma civilização em mudança. \\
\hline
\end{tabular}

Fonte: Acervo Professor Faris Michaele.

Nota: Os autores. 
Em termos gerais, as matrizes teóricas e filosóficas do pensamento moderno que mobilizaram o debate educativo contemporâneo faziam parte do horizonte intelectual de Faris Michaele. John Dewey (Filosofia), Emille Durkheim (Sociologia),
Willian Kilpatrick (Psicologia) e Jean Piaget (Psicologia e Biologia), alguns dos principais interlocutores dos defensores da pedagogia moderna no Brasil, compunham o acervo da biblioteca pessoal de Faris Michaele.

QUADRO 2 - Relação de obras de autores brasileiros do Movimento da Escola Nova que compõem o acervo da Biblioteca Pessoal de Faris Michaele

\begin{tabular}{|l|l|}
\hline \multicolumn{2}{|c|}{ Relação de obras de autores brasileiros do Movimento da Escola } \\
Nova que compõem o acervo da Biblioteca Pessoal de Faris Michaele \\
\hline Autores & Obras \\
\hline Anísio Teixeira & Pensamento e ação (1960). \\
\hline \multirow{5}{*}{ Fernando de Azevedo } & As ciências no Brasil; \\
& A cultura brasileira I, II, III (1958); \\
& A educação e seus problemas (1946); \\
& Canaviais engenhos na vida política do \\
& Brasil; \\
& Eáscaras e retratos (1962); \\
& Na batalha do humanismo (1952); \\
& No tempo de Petrônio: ensaios sobre \\
& antiguidade latina (1962); \\
& Princípios de sociologia (1935); \\
& Sociologia educacional (1954). \\
\hline Lourenço Filho & Introdução ao estudo da Escola Nova (1929). \\
\hline
\end{tabular}

Fonte: Acervo Professor Faris Michaele Nota: Os autores.

Os principais personagens da Escola Nova ${ }^{2}$ no Brasil estavam entre os interlocutores de Faris Michaele, principalmente Fernando de Azevedo. A presença de Anísio Teixeira, Lourenço Filho e
Fernando de Azevedo indica que Michaele acompanhava atentamente a recepção no Brasil do projeto societário e educativo propugnado pelos defensores da Pedagogia Moderna.

\footnotetext{
${ }^{2}$ Escola Nova é a definição mais conhecida do movimento da pedagogia moderna. A rigor, são utilizadas outras denominações, como, por exemplo: Escola Ativa, Escola Progressiva, Escola Moderna, Pedagogia Moderna, Pedagogia Contemporânea.
} 
QUADRO 3 - Relação de obras de autores paranaenses que compõem o acervo da Biblioteca Pessoal de Faris Michaele

\begin{tabular}{|l|l|}
\hline \multicolumn{2}{|c|}{ Relação de obras de autores paranaenses que compõem o acervo da } \\
Biblioteca Pessoal de Faris Michaele
\end{tabular}

Fonte: Acervo Professor Faris Michaele.

Nota: Os autores.

A presença significativa de obras de Erasmo Pilotto e Valfrido Piloto-educadores associados ao grupo da pedagogia moderna - evidencia a relação de Faris Michaele com o pensamento filosófico dessa tradição teórica. A vinculação de Erasmo Pilotto ao Movimento da Escola Nova (MEN) é narrada de forma precisa por Vieira e Marach (2007, p. 272): "Pilotto, partícipe dessa atmosfera intelectual, vinculou-se ao MEN ainda no seu tempo de aluno da Escola Normal. Fundou, nesse período, o Centro de Cultura Filosófica, o Centro de Cultura Pedagógica e o boletim O ideário da escola nova”. Além disso, observam os autores (p. 272): "No plano teórico, Tólstoi e Rousseau foram os interlocutores da juventude, enquanto na maturidade, sem abandonar essas fontes, incorporou criticamente as mais significativas idéias dos movimentos europeu, norte-americano e brasileiro”.
Em síntese, pela relação das obras sobre educação que compõem a biblioteca pessoal de Faris Michaele, assim como pela vinculação de amizade que mantinha com os protagonistas da Escola Nova no Paraná, é possível sustentar que suas leituras e discussões no campo pedagógico aproximavam-se dos princípios da pedagogia moderna. Tal assertiva indica que, no conjunto de livros da área de educação da biblioteca de Faris Michaele, sobressaemse as obras associadas ao movimento da pedagogia moderna. Desse modo, compreendemos que esses dois elementos (amizade com o grupo da Escola Nova do Paraná e presença significativa de obras de autores do movimento da escola moderna) constituem indícios suficientes para afirmar uma aproximação entre o pensamento de Faris Michaele e o ideário da 
pedagogia moderna. Entretanto, é necessário realizar outras pesquisas para avançar na confirmação dessa hipótese, particularmente realizar investigação mais precisa sobre o pensamento educativo de Faris Michaele. Tal tarefa deverá ser feita a partir das obras desse intelectual paranaense, pois a história intelectual tem a pretensão de articular os aspectos externos (contextos) e elementos internos (textos). Neste artigo, privilegiamos os aspectos de caráter sociológico (rede de amizade, filiação institucional, biblioteca pessoal). Por outro lado, o aspecto filosófico (ideias) assumiu um sentido menor em nossa pesquisa, o que indica uma lacuna que deverá ser minimizada com outras investigações. No entanto, reiteramos que a nossa pretensão ao escrever este texto consistia em reconstituir alguns aspectos da trajetória de Faris Michaele para evidenciar a hipótese de que esse personagem articulava sua intervenção intelectual aos ideários da modernidade e da pedagogia moderna.

\section{Considerações finais}

Este texto, ao problematizar alguns aspectos da trajetória intelectual de Faris Michaele, contribui para indicar que, além do eixo Rio - São Paulo, o restante do Brasil também discutiu os rumos da sociedade e promoveu uma intensa ação e produção intelectual. Nesse sentido, os meios de comunicação, embora fossem precários, permitiam a difusão e a formação de visões de mundo.

As cartas e periódicos que compõem o acervo de Faris Michaele demonstram o intercâmbio de ideias, elogios e críticas a respeito das problemáticas do mundo moderno. Em linhas gerais, é possível afirmar que Michaele entendia que "o desafio contemporâneo está em realizar a utopia na modernidade, tal como ela se apresenta a partir do século XIX. Isto é fazer da modernidade uma experiência baseada na ciência e na técnica, vivida a partir da Europa, não mais em ilhas ou terras distantes" (PAZ, 1994, p. 7).

Educação e cultura, elementos chaves para a modernidade, foram temáticas recorrentes nos escritos e na trajetória profissional de Faris Michaele. Desde a juventude até o fim da sua vida, ele criou e participou de espaços culturais, além da dedicar-se ao magistério. Esteve vinculado à criação de diversos ambientes da vida cultural de Ponta Grossa - como, por exemplo, a Faculdade de Filosofia, Ciências e Letras - os quais expressam sua preocupação em estabelecer na cidade os principais ícones da então denominada sociedade moderna, pois "mais do que sonhos insólitos, utopia e modernidade configuram o real oitocentista" (PAZ, 1994, p. 7).

Tal observação indica que a trajetória de Faris Michaele está associada a uma camada social que acreditava em seu papel de organização e divulgação de visões de mundo que expressassem os valores da filosofia e da ciência modernas. Os ambientes culturais estabelecidos por Michaele e seus amigos pretendiam constituir-se com certa autonomia em relação aos poderes políticos, religiosos e econômicos. Tal pretensão expressa o desejo da própria condição do campo intelectual: constituir-se com relativa independência em relação aos outros campos sociais. É nesse sentido que a hipótese bourdieusiana é fecunda para interpretar a trajetória intelectual de Michaele, pois ele percorreu permanentemente espaços culturais que se pretendiam autônomos, o que contribuiu para que figurasse numa classe de intelectuais de múltiplas expressões políticas, religiosas, filosóficas e teóricas no Centro Euclides da Cunha e na própria Faculdade de Filosofia, Ciências e Letras de Ponta Grossa.

Portanto, a partir da discussão de alguns aspectos da história de Faris Michaele 
foi possível indicar sinais da própria história cultural e educativa da cidade de Ponta Grossa, pois a escrita da trajetória desse personagem está associada à história de instituições que tiveram papel importante no processo de constituição dessa cidade ao longo do século XX. A vinculação de Michaele à imprensa (Diário dos Campos, Tapejara), aos centros culturais (Centro Cultural Euclides da Cunha), às instituições escolares (Colégio Regente Feijó/Faculdade de Filosofia, Ciências e Letras) evidencia que reconstituir sua trajetória representa discutir sobre parte significativa das instituições culturais e educativas ponta-grossenses do século XX.

\section{Fontes}

MANUSCRITOS. Enrique de Gandía. Buenos Aires, 1948.

MANUSCRITOS. Alcantara Nogueira. Rio de Janeiro, 1949.

PILOTO, V. Tupi e grego, do professor Michaele e a Universidade Estadual de Ponta Grossa. Diário do Paraná, Ponta Grossa, p. 2, 7 mar. 1974.

\section{Referências}

ANDRADE, M. L. Dario Vellozo e a escola moderna: a renovação do pensamento educacional no Paraná (1906-1918). In: VIEIRA, C. (Org.). Intelectuais, educação e modernidade no Paraná (1886-1964). Curitiba: Editora UFPR, 2007.

BOURDIEU, P. As regras da arte: gênese e estrutura do campo literário. São Paulo: Companhia das Letras, 1996a.

Escritos de educação. Petrópolis: Vozes, 2007.
. Economia das trocas lingüísticas:

o que falar quer dizer. São Paulo: Edusp, 2008.

. Questões de sociologia. Rio de Janeiro: Marco Zero, 1983.

Razões práticas: sobre a teoria da ação. Campinas: Papirus, 1996b.

DITZEL, C. H. M. O arraial e fogo da cultura: os euclidianos ponta-grossenses. Ponta Grossa, 1998. Dissertação (Mestrado em Educação) - Universidade Estadual de Ponta Grossa, Ponta Grossa.

. Imaginário e representações: o integralismo dos Campos Gerais (1935-1955). Ponta Grossa: UEPG, 2007.

GOMES, J. M. L. O. Descrição bibliográfica do acervo professor Faris Michaele. Winisis. Ponta Grossa: Editora UEPG, 2009.

LE GOFF, J. História e memória. Campinas: Unicamp, 1990.

MARÇAL, M. A. Regente Feijó: memórias de uma escola. In: VEIGA, Z. (Org.). Visões de Ponta Grossa. Curitiba: Pós-Escritos, 2006.

MICELI, S. Intelectuais à brasileira. São Paulo: Companhia das Letras, 2001.

MONARCHA, C. A reinvenção da cidade e da multidão: dimensões da modernidade brasileira: a Escola Nova. São Paulo: Cortez, 1989.

NOGUEIRA, M. A.; NOGUEIRA, C. M. M. Bourdieu e educação. 3. ed. Belo Horizonte: Autêntica, 2009. (Pensadores e educação, v.4).

OLIVEIRA, J. C. de. Educadores ponta-grossenses (1850 - 1950). Ponta Grossa: Editora UEPG, 2002. 
PAZ, F. M. Utopia e modernidade: a nostalgia da transparência. In: Utopia e modernidade. Curitiba: UFPR, 1994, p. 7-14.

PILOTO, O. Faris Michaele. Minerva - Revista da Faculdade Estadual de Filosofia, Ciências e Letras de Ponta Grossa, Ponta Grossa, n. 2, p. 5-7, 1968.

SILVA, H. R. Fragmentos da história intelectual: entre questionamentos e perspectivas. Campinas: Papirus, 2002.

SILVA, R. A arte como princípio educativo: um estudo sobre o pensamento educacional de Erasmo Pilotto. 2009. Dissertação (Mestrado em Educação). Programa de Pós-Graduação em Educação, Universidade Federal do Paraná, Curitiba, 2009.

SOUZA, E. F. Intelectuais, modernidade e discurso educativo no jornal Diário dos Campos (1907-1928). 2010. Dissertação (Mestrado em Educação). Programa de Pós-Graduação em Educação, Universidade Estadual de Ponta Grossa, Ponta Grossa, 2010.

VIEIRA, C. E. Intelectuais e discurso da modernidade na I Conferência Nacional da Educação (Curitiba-1927). In: BENCOSTTA, M. L. A. (Org.). Culturas escolares, saberes e práticas educativas: itinerários históricos. São Paulo: Cortez, 2007.

VIEIRA, C. E.; MARACH, C. B. Escola de mestre único e escola serena: realidade e idealidade no pensamento de Erasmo Pilotto. In: VIEIRA, C. (Org.). Intelectuais, educação e modernidade no Paraná (1886-1964). Curitiba: UFPR, 2007.

WANKE, E. T. Faris Michaele: cronologia da vida e da obra. Rio de Janeiro: Edições Plaquette, 1998.
ZULIAN, R. W. A victoriosa rainha dos campos: Ponta Grossa na conjuntura republicana. Revista de História Regional, Ponta Grossa, v. 03. n. 02, p. 37-76, 1998.

Enviado em: 02/06/2010

Aceito em: 13/12/2010 